\title{
Antituberculosis Drugs Induced Hepatitis
}

\author{
Niyati Patel, Riya Gandhi, Padmja Dave, Mahek Mistry
}

Department of Pharmacy, Sumandeep Vidyapeeth (Deemed To Be University), Pipariya, Waghodiya, Vadodara, Gujarat, INDIA.

\begin{abstract}
Background: Tuberculosis, also called as TB, is a highly contagious bacterial infection and can be found nearly anywhere in the body, but lungs are the most common site of infection. Among the first line combination therapy drugs (INH, RMP, PZA, EMB), $I N H$, RMP, and PZA are hepatotoxic as they are potentially metabolized mainly by the liver. Case: This is a case report of 18 years old male patient who was diagnosed with hepatitis after administration of anti TB drugs. He was admitted to the hospital for dry cough, loss of appetite, weight loss $3-5 \mathrm{~kg}$ before 1 month. Laboratory investigations and other reports confirmed hepatitis. In this case, patient was receiving the anti TB drugs since 1 month and then later developed hepatitis which is a severe adverse drug reaction. Conclusion: Although hepatotoxicity is severe side effects of antituberculosis drugs. Following standard treatment and care of the patient we archive favourable outcome.
\end{abstract}

Key words: Anti tubercular drugs, Hepatitis, SGOT, SGPT, Adverse Drug Reaction.

\section{INTRODUCTION}

- According to WHO, India has the world's largest tuberculosis epidemic. ${ }^{1}$ In India, TB causes the death of every third aids patient. Furthermore, india accounts for around one fourth of the global tuberculosis burden. ${ }^{2}$

Tuberculosis also called as $\mathrm{TB}$, is a contagious bacterial infection and is found nearly anywhere in the body, but most commonly it is found in the lungs. This is because, mycobacterium tuberculosis, the bacteria that is responsible for $\mathrm{TB}$ infection is spreadthrough the air as it cannot live long on surfaces. When people suffering with lung TB sneeze, cough or spit, they propel these micro-organisms in their immediate surroundings. Upon the inhalation of only a few germs a person can become infected. Although discovered more than a 100 years ago, tuberculosis still one of the disease that cause the most deaths every year. Tuberculosis is a curable and preventable. ${ }^{2}$
Currently, the recommended first-line treatment for TB isisoniazid (INH), rifampicin (RMP), pyrazinamide (PZA) ethambutol (EMB) given for 2 months, followed by isoniazid and rifampicin or ethambutol for 4 months. Hepatotoxicity is most occurring serious adverse effect of anti-TB medications and may reduce treatment effectiveness by compromising the treatment regimens. ${ }^{2,3}$

Among the first-line quadruple therapy of drugs these INH, RMP, and PZA drugs are metabolized mainly by the liver and responsible for causing hepatotoxicity. According to many studies $2-28 \%$ cases were reported for Anti-TB Drug-Induced Hepatotoxicity. ${ }^{4}$

The risk factor for anti-TB induced hepatotoxicity includes history of chronic liver disease, or an infection of the liver like chronic viral infection, hepatitis $B$ (HBV), hepatitis $\mathrm{C}(\mathrm{HCV})$, high intake of alcohol, elderliness, advanced TB, HIV infection, associated administration of
DOI: 10.5530/ijopp.14.4.62

Address for correspondence: Niyati Patel,

Pharm.D Intern, Department of Pharmacy, Sumandeep Vidyapeeth (Deemed To Be University), Pipariya, Waghodiya, Vadodara, Gujarat, INDIA. Phone no: +91-9638782155 Email id: niyatipatel640@ gmail.com

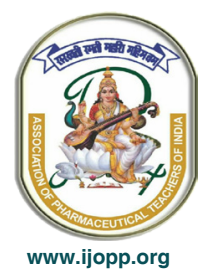


enzyme-inducers, drug dependence and malnutrition status. ${ }^{2,5,6}$ The aim of the study was to assess the risk factors, observe the approach and outcome of anti-TB medication, assess alteration ion liver enzyme and report the adverse effect of hepatotoxicity associated with antiTB medication in a tertiary care hospital patient.

\section{CASE REPORT}

A 18-year-old male patient came with complaints of dry cough, weight loss 3-5 kg, jaundice since 4 days, loss of appetite, yellowish discoloration of skin since 4 days. The patient was addicted to alcohol. The patient was diagnosed with pulmonary TB since 1 year, he had taken anti-TB drug.

On the $1^{\text {st }}$ day patient was came to the hospital with pulse rate $96 / \mathrm{min}, \mathrm{BP}$ is found to be $110 / 68 \mathrm{mmHg}$ with $\mathrm{SPo}_{2} 96 \%$ with high flow oxygen. The patient was asked for following investigations: serum creatinine, blood urea, liver function test, USG rest, chest X ray. Based on laboratory findings and USG reports patient diagnosed with borderline hepatitis. On the basis of medicine reference patient was diagnosed with pulmonary thromboembolism with anaemia and advise on further management by giving the patient IV iron parenteral therapy of blood transfusion $\left(\mathrm{B}^{+\mathrm{ve}}\right)$. The patient received the following medications,

- Inj. Streptomycin 0.75gm (1-0-0)

- Tab. Levofloxacin 750 mg (1-0-0)

- Tab. Ethambutol 1000 mg(1-0-0)

- Neb. Levosalbutamol(1.25 mcg) + Ipratropium bromide $(500 \mathrm{mcg})(1-1-1-1)$

- $\quad$ Neb. Budesonide 0.5 mg (1-0-1)

- Inj. Normal saline $1 \mathrm{amp}$

- Inj. Ondansetron 4 mg (1-0-1)

- Tab. Paracetamol 500 mg (1 tab SOS)

On the $2^{\text {nd }}$ day physician prescribed medicine that is Tab. Folic acid $(5 \mathrm{mg})+$ mecobalamine $(1500 \mathrm{mg})+$ pyridoxine (20mg) with frequency of (0-1-0) to the patient after examination.

On the $3^{\text {rd }}$ day $\mathrm{BP}$ was recorded $102 / 70 \mathrm{mmHg}$ and pulse rate was $110 / \mathrm{min}$. The patient was received following medicine and rest of the treatment was continued same as before.

- Inj. Etophyline $(84.7 \mathrm{mg})+$ Theophyline $(25.3 \mathrm{mg})$ $(1-0-1)$

- Inj. Enoxaparine 60 mg (1-0-1)

- Tab. Potassium chloride ( 2 tsf in $1 / 2$ glass of water) (1-1-1)

- Tab. Ferrous ascorbate (100mg) + Folic acid $(1.5 \mathrm{mg})$ $(1-0-1)$

- Inj. Hydrocortisone (100mg) (1/2-1/2-1/2)

\begin{tabular}{cccc}
\hline \multirow{2}{*}{ Parameter } & \multicolumn{2}{c}{ Test values } & Normal range \\
\cline { 2 - 3 } & Day 1 & Day 2 & \\
LFT & & & \\
SGOT & 41 & 45 & Upto $40 \mathrm{IU} / \mathrm{L}$ \\
SGPT & 39 & 43 & Upto $40 \mathrm{IU} / \mathrm{L}$ \\
Total Bilirubin & 1.3 & 1.0 & $1.2 \mathrm{mg} / \mathrm{dl}$ \\
Direct Bilirubin & 0.4 & 0.4 & $0.3 \mathrm{mg} / \mathrm{dl}$ \\
Lymphocytes & 16 & & 20 to $40 \%$ \\
Platelets & 1.3 & & 1.5 to $2.5 \mathrm{Lac}$ \\
Urine Analysis & & & \\
Albumin & ++ & & \\
Sugar & ++++ & & \\
Acetone & ++ & & \\
Calcium Oxalates & $1-2$ & & \\
USG & & & \\
Abdomen & & Borderline & \\
& & hepatitis &
\end{tabular}

On the $4^{\text {th }}$ day BP was recorded $110 / 68 \mathrm{mmHg}$ and Pulse rate $90 / \mathrm{min}$ with $\mathrm{SPo}_{2}$ concentration $95 \%$, other examination that is sputum for AFBRNTCP - is CABNAAT positive (Rifampicin sensitive). The patient was prescribed with Tab. Isoniazid $(300 \mathrm{mg})$ and rest of treatment was continued.

On the $5^{\text {th }}$ day, nutritional assessment was performed, the patient was on low protein, low fat liquid, liquid food, same treatment was continued.

On the $6^{\text {th }}$ day, No fresh complain was seen and the same treatment was continued.

On day 7, the patient was diagnosed with antituberculosis drugs induced hepatitis.

On the $8^{\text {th }}$ day, the patient complains of episode of anxiety, sadness of mood and panic attack, which was evaluated by psychiatrist who prescribed the following medication and plan for discharge was made.

- Tab. Fluoxetine $60 \mathrm{mg}(1-0-1)$ 
- Tab. Clonazepam (0.5mg) (0-0-1)

On the $9^{\text {th }}$ day patient was discharge with discharge medication chart and counselling on his medication.

\section{Causality Assessment}

Causality and severity assessment has done with the help of five different scales and results are following:

\begin{tabular}{cc}
\hline Scale's Name & Result \\
\hline WHO & Probable \\
Naranjo's algorithm & Probable \\
Shumock and thronton & Definitely \\
Karch and lasagne & Probable \\
Hartwigs and siegel & Predictable \\
\hline
\end{tabular}

\section{DISCUSSION}

Anti-Tuberculosis drugs induced hepatotoxicity is a serious problem and 2-28\% cases reportedAnti-TB drug-induced Hepatotoxicity (DIH) during their course of treatment. Viral hepatitis has been replaced with Drug induced liver disorder even acute liver failure. Drug-induced liver disorder is diagnosed only after excluding viral hepatitis. The prevalence of drug induced hepatotoxicity in India is found to be around 8-36\%. ${ }^{7}$ Asian countries have higher incidence of $\mathrm{DIH}$ which may be due toasian ethnic susceptibility and/ or the presence of various known predisposing factor such as HBV infection, and undernutrition and anemia in these regions. According to a studyconducted, the overall frequency of serious adverse effects was three times higher with Pyrazinamide than with isoniazid, or rifampicin. It is also found that malnutrition is the main risk factors that lead to hepatotoxicity due to anti-TB medications. In our case upon nutritional assessment, patient was found with lacking protein and other nutrients consistent with history of malnutrition. Patient was also found to be underweight. ${ }^{7,8}$ Many studies show strong evidence that malnutrition is strong predictor of ATT induced hepatoxicity. ${ }^{9-11}$

The risk factors for Anti TB drug induced hepatotoxicity also include geriatric patients, female gender, under nourishment, alcohol consumption, history of liver diseases, Extra pulmonary $\mathrm{Tb}$ affecting abdomen and infections such as HIV and Hepatitis B and C. However, the mechanism of biochemical reaction and pathogenesis of Anti TB drug induced hepatotoxicity remains uncertain. Liver is an important body organ according to physiological point of view as it is responsible for metabolism of many xenobiotic. The prevalence of hepatotoxicity is found to be $2.6 \%$ with combination of INH (Isoniazid) and Rifampicin, 1.1\% with Rifampicin Monotherapy and 1.6\% with isoniazid Monotherapy only. ${ }^{12}$

According to Naranjo Causality Assessment Algorithm Antitubercular agents are probable to cause hepatotoxicity.Upon discharge, the patient was counselled regarding the medications and duration of the treatment.

\section{CONCLUSION}

We reported a case of anti-tuberculosis drugs induced hepatitis in 18-year-old male patient. Although hepatotoxicity is severe side effects of anti-tubercular drugs. Following standard treatment and care we have archive outcome. It is important for physician and pharmacist to follow up patient, counsel them about signs and symptoms of of hepatitis and encourage them to report it.

\section{ACKNOWLEDGEMENT}

Authors sincerely thankful to all the members of Department of Pharmacy, Sumandeep Vidyapeeth (Deemed to be University) for their support. Strength of the study

The present study reviews the prescribing pattern for anti tuberculosis drug induced hepatitis. The study can be utilized by the researchers in direct to carry out the same at larger sample size.

\section{CONFLICT OF INTEREST}

The authors declare no conflict of interest.

\section{ABBREVIATIONS}

AFB: Acid Fast Bacili; ADR: Adverese Drug Reaction; ATT: Anti Tuberculosis Treatment; AMC: Adverse Drug Reaction Monitoring Centre; BP: Blood Pressure; CABNAAT: Cartridge Based Nucleic Acid Amplification Test; EMB: Ethambutol; gm: Gram; HBV: Hepatitis B Virus; HIV: Human Immunodeficiency Virus; INH: Isoniazid; Ing: Injection; Mg: Miligram; Mcg: Microgram; Neb: Nebulizer; PZA: Pyrazinamide; RMP: Rifampicin; RNTCP: Revised National TB Control Programme; SGOT: Serum Glutamic Oxeloacetic acid; SGPT: Serum Glutamic Pyruvic Transaminase; SOS: Si Opus Sit (Immediately); TB: Tuberculosis; Tab: 
Tablet; USG: Ultrasonography; WHO: World Health Organization.

\section{REFERENCES}

1. World Health Organization. Global tuberculosis report 2012. Geneva: World Health Organization; 2012.

2. World Health Organization. Treatment of tuberculosis [guidelines]. 4th ed. Geneva: World Health Organization; 2010.

3. Blumberg HM, Burman WJ, Chaisson RE, Daley CL, Etkind SC, Friedman LN, Fujiwara P, Grzemska M, Hopewell PC, Iseman MD, Jasmer RM, Koppaka V, Menzies RI, O'Brien RJ, Reves RR, Reichman LB, Simone PM, Starke JR, Vernon AA, American Thoracic Society, Centers for Disease Control and Prevention and the Infectious Diseases Society. American Thoracic Society/ Centers for Disease Control and Prevention/Infectious Diseases Society of America: treatment of tuberculosis. Am J Respir Crit Care Med. 2003;167(4):60362. doi: 10.1164/rccm.167.4.603, PMID 12588714.

4. Girling DJ. The hepatic toxicity of antituberculosis regimens containing isoniazid, rifampicin and pyrazinamide. Tubercle. 1978;59(1):13-32. doi: 10.1016/00413879(77)90022-8, PMID 345572.

5. Tostmann A, Boeree MJ, Aarnoutse RE, de Lange WCM, van der Ven AJ, Dekhuijzen R. Antituberculosis drug-induced hepatotoxicity: concise up-todate review. J Gastroenterol Hepatol. 2008;23(2):192-202. doi: 10.1111/j.14401746.2007.05207.x, PMID 17995946.
6. Breen RA, Miller RF, Gorsuch T, Smith CJ, Schwenk A, Holmes W, Ballinger J, Swaden L, Johnson MA, Cropley I, Lipman MC. Adverse events and treatment interruption in tuberculosis patients with and without HIV co-infection. Thorax. 2006;61(9):791-4. doi: 10.1136/thx.2006.058867, PMID 16844730.

7. Khalili H, Dashti-Khavidaki S, Rasoolinejad M, Rezaie L, Etminani M. Antituberculosis drugs related hepatotoxicity; incidence, risk factors, the pattern of changes in liver enzymes and outcome. Daru. 2009;17(3).

8. Wondwossen Abera, Waqtola Cheneke, Gemeda Abebe. Incidence of antituberculosis-drug-induced hepatotoxicity and associated risk factors among tuberculosis patients in Dawro Zone, South Ethiopia: A cohort study. Int J Mycobacteriol. 2016;5(1):14-20. doi: 10.1016/j.ijmyco.2015.10.002. PMID 26927985.

9. Larrey D. Epidemiology and individual susceptibility to adverse drug reactions affecting the liver. Semin Liver Dis. 2002;22(2):145-55. doi: 10.1055/s-200230105, PMID 12016546.

10. Shakya R, Rao BS, Shrestha B. Incidence of hepatotoxicity due to antitubercular medicines and assessment of risk factors. Ann Pharmacother. 2004;38(6):10749. doi: 10.1345/aph.1D525, PMID 15122004.

11. Sarma GR, Immanuel C, Kailasam S, Narayana AS, Venkatesan P. Rifampininduced release of hydrazine from isoniazid. A possible cause of hepatitis during treatment of tuberculosis with regimens containing isoniazid and rifampin. Am Rev Respir Dis. 1986;133(6):1072-5. doi: 10.1164/arrd.1986.133.6.1072, PMID 3717759.

12. Yew WW, Leung CC. Antituberculosis drugs and hepatotoxicity. Respirology. 2006;11(6):699-707. doi: 10.1111/j.1440-1843.2006.00941.x, PMID 17052297. 